\title{
Emerging Culture and cultural capital: The case of yoga, meditation and vegetarianism in the U.K. ${ }^{1}$
}

\author{
Adam Gemar
}

2018

\begin{abstract}
Yoga and meditation have experienced a boom in Western appropriation in recent decades and consistently grow more culturally ubiquitous. Likewise, rates of vegetarianism increase every year. However, little scholarly work has been produced around these newer forms upon the cultural landscape. This paper seeks to remedy this fact. It aims to advance understandings as to the patterns of consumption regarding newer cultural forms, with yoga, meditation, and vegetarianism as case studies. Proceeding with the U.K. as the field of study, this paper presents an original national survey. It performs a multiple correspondence analysis and multinomial logistic regressions with the survey data to accomplish a topographical mapping and bivariate analysis of consumption and interaction with these cultural forms. Through this empirical and statistical analysis, it asserts that objectified cultural capital is still important for the social distinction associated with participation patterns of these forms. These emerging forms of culture are thus rarefied in a way that more closely resembles traditionally highbrow cultural forms.
\end{abstract}

Keywords: Bourdieu; cultural capital; emerging culture; meditation; yoga; vegetarian

${ }^{1}$ This is an original manuscript / preprint of an article that has been accepted for publication in Leisure/Loisir, published by Taylor \& Francis. 


\section{Introduction}

The yoga industry in the U.K. brings in revenues in excess of $£ 800$ million, growing faster than the economy at large (IBIS, 2016). Large corporations, such as Google (Shachtman, 2013), integrate meditation into their daily processes for inspiration, rejuvenation, and ultimately, productivity and profits (Davies, 2016; Lau, 2000; Shachtman, 2013). The worldwide meditation industry is over one billion dollars (Fortune, 2016). The U.K. market for vegetarian food is in the hundreds of millions of pounds, growing yearly (Mintel, 2014). While the business of these forms is indeed large, the cultural footprint of that these figures represent is likewise substantial. Indeed, many celebrities are outspoken proponents of one or more of these patterns of behaviour. While these topics have certainly been researched before (almost exclusively separately) in the fields of Psychology and Religious Studies, this is the first empirical sociological study that the author is aware of that includes considerations of all three of yoga, meditation and vegetarianism in an analysis of the wider cultural landscape from a cultural consumption perspective. Most previous research into these forms are in the format of experimental studies and/or clinical trials (Park, Braun, and Siegel, 2015). Even as these forms have been studied in these disciplines and using these methods, there is still generally little published research in sociology that focuses on yoga (Hasselle-Newcombe, 2005). Therefore, these forms are both popular but have been under-researched (HasselleNewcombe, 2005). This paper proceeds from the assertion that these practices are important aspects of culture on the social landscape of the UK. There is interest in these forms emanating from various domains of society. These practices are growing, yet there is currently a dearth of sociological (and especially quantitative) work regarding their consumption and the social distinctions that may accompany with their engagement. This is true even as participants in these forms surpass many of the more traditional cultural categories such as going to the opera and listening to jazz. This research seeks to assess 
cultural engagement with these forms. To forward this aim, this paper asks the following questions:

1. Where are the different cultural forms of yoga, meditation, and vegetarianism located relationally to more established cultural forms on the cultural map of the United Kingdom?

2. Who engages in these forms?

3. Does there exist relevant social cleavages in this consumption that lend to prevailing theories of culture and cultural consumption?

These three practices are chosen for this paper for many reasons. One reason is their prevalence on the contemporary cultural landscape of the UK, as evidenced above and in the original survey conducted for this study. They are also generally understudied in sociology. Other forms of culture may be equally efficacious. However, another point of analytical importance of these forms originates from their rapid proliferation in recent decades. Therefore, they represent nodes of inquiry into distinctively 'emerging' forms of culture. However, many cultural forms may also fit this description (and these could and should also be studied). These practices are also important because they have strong intersections with sociologies of the body, globalisation, and sociologies of religion.

Considerations of these aspects are interwoven with a class analysis that takes culture into account as a site of symptomatic and emblematic social inequality. The findings of this paper confirm previous findings of the fault lines of cultural behaviours in the contemporary UK as now primarily based upon whether or not one is culturally engaged as opposed to which forms of culture are engaged (Bennett et al., 2009; Savage et al., 2015). However, it problematises some of the assertions that these differences in which forms of culture are consumed are primarily generational in nature and that 'emerging' cultural forms (i.e. comedy) are the realm of the (cultural) capital possessed younger generation, while more 
traditional forms of culture (i.e. opera) are entrenched in the cultural engagement of older generations (Bennet et al., 2009; Savage et al., 2013; Friedman, 2014).

More generally, a generational difference in the consumption of culture is well supported in recent literature (Purhonen et al., 2011; Lizardo and Skiles, 2015; Roose, 2015). However, in the form of yoga, meditation and vegetarianism we see locations of cultural engagement that present as both relatively new to the cultural landscape and relatively 'highbrow', challenging claims that these new forms of culture present as primarily more 'lowbrow', or rather 'emerging', forms (Prieur and Savage, 2013). These are less established elements of culture that may often be termed lowbrow but because of the class make up of their participation as being that of primarily middle class, educated, youths, 'emerging' is preferred to lowbrow by some to more accurately assess the place of these activities on the cultural landscape (Savage et al, 2015). This paper argues that yoga, meditation and vegetarianism represent new and more 'trendy' cultural forms that still present themselves quantitatively as possessing the ability to convey types of 'objectified' cultural capital. This is cultural capital that is more explicitly based upon whether or not one engages in these activities, rather than how one engaged with them.

When new cultural forms appear on the social landscape, there are contestation and consecration processes by which their existence as highbrow or lowbrow is a fluid process. Opera and Jazz are prime examples of this kind of historical contestation through which these forms, having originally been forms of marginalised classes in their original contexts, ultimately arrived as consecrated highbrow forms on the cultural landscape. Yoga and meditation are activities that can be practiced free of charge if one chooses. In the case of vegetarianism, the cost of meat makes this lifestyle choice little or no more expensive than other diets. It is all the more important that activities that are easily accessible, such as yoga 
and meditation, appear to already be consecrated at similar levels as going to the theatre. These emerging forms of culture may thus represent rarefied forms of cultural participation that have been rapidly consecrated to the level of traditional forms of highbrow culture, bridging the age divide between emerging and more established forms of culture. This paper starts with a discussion to theoretically situate the analysis. It then delves into a statistical analysis of survey data to answer the research questions.

\section{Capital and Consumption}

Bourdieu found great difference in the forms of culture that were engaged in by the different classes of France. Those of higher occupational and class status and higher educational qualification engaged themselves in 'legitimate', or 'highbrow' - culture and 'high' art forms (Bourdieu, 1984). These are forms that are consecrated in societies as being of high intellect and of high taste - for example, going to the theatre or the opera. The elites of society are ultimately the group that designates the consecration of these specific activities. Societal elites argue that these cultural forms are more difficult to do, more intellectual, and therefore access to them is limited. This access is limited because of the perceived skill involved, along with more formal barriers. These more formal barriers to access to these cultural activities include access to educational opportunities and locations in members only clubs and organisations. Access is perhaps most limited by the type of economic resources necessary for their engagement. However, among the higher classes, this final consideration is lumped into the first two considerations of necessary 'natural' skill and intellect in a process that pathologises those with lower economic (and cultural) capital as unable to engage in these forms for lack of intelligence or skill. They are also consecrated in society by being enshrined in institutions such as theatres and museums, supported by governments both monetarily and otherwise, and enshrined in school curricula. Because these forms are institutionalised as such, they are also the 'established' culture. Cultural capital is thus 'institutionalised, i.e., 
widely shared, high status cultural signals (attitudes, preferences, formal knowledge, behaviors, goods and credentials) used for cultural and social exclusion' (Lamont and Lareau, 1988: 153).

Bourdieu (1984) argued that cultural choices had the ability to accumulate cultural capital that then could be used to reinforce social position. This cultural capital can be exchanged in ways that also accrued social and ultimately economic capital. However, these cultural choices, and their subsequent accumulative effect are structurally constrained by societal structures and social class. Bourdieu (1984) asserted that this cultural capital was accumulated through primary socialisation of children. This was a process whereby those from better educated and well off families were instilled from an early age with an appreciation and competence in more 'legitimate' forms of culture than their less advantaged counterparts. Because of the internalised character of this appreciation, it was 'embodied' (Bourdieu, 1986). It was also then often misconstrued by the education system as natural intelligence (Bourdieu, 1984; Bourdieu and Wacquant, 1992), as they possessed knowledge of the institutionally consecrated cultural objects of appreciation.

'Distinction' is thus produced and reproduced out of the cultural capital possession of the higher classes. This includes two distinct but inexorably linked parts of cultural capital, embodied cultural capital and objectified cultural capital. There were thus stark social distinctions based upon the type of culture that one engaged (objectified cultural capital) and the sophistication with which one could innately discuss and appreciate these highbrow art forms (embodied cultural capital).

Bourdieu (1984: 3-89) describes a 'disinterested aesthetic' or an 'aesthetic distancing' and the impact that primary socialisation and 'educational capital' has in cultivating such a disposition, or what Bourdieu characterises as this embodied cultural capital (Bourdieu, 
1986). For Bourdieu, objectified cultural capital is a manifestation of embodied cultural capital, by which the privileged objectify their cultural knowledge. They convert their cultural capital and cultural knowledge into implicit and explicit tastes and consumption patterns of legitimate culture and 'highbrow' art forms. The consumption of these objects is a symbolic marker of social status. Because these objects of high and legitimate culture require high levels of cultural capital in order to consume them 'correctly', the embodied state of cultural capital is inextricably linked to its symbolic manifestation that is its objectified state. This interplay, and the social and internal processes that develop it, is, for Bourdieu, a product of one's 'habitus' (Bourdieu, 1984). Bourdieu argued that our cultural choices are structured by class based, primarily and secondary socialised constitutions. They are structurally patterned by one's 'habitus'. Bourdieu's habitus is the class-based dispositions of the individual that subsequently structures taste and social action (Bourdieu, 1984).

Bourdieu (1984) asserted the existence of cultural homologies as a product of this unified habitus. Bourdieu's framework asserts that one's habitus leads to homologies of taste and consumption across the various domains of culture. These homologies are thus a product of the habitus in that if the habitus is socialised and internalised as a class based phenomena and a function of class based constitutions, then homologies of taste are also a function of these class based processes. Because the classes are defined against each other, so too is the habitus of the individual and the homologies of taste that structure their cultural consumption. 'Lowbrow' cultural forms are thus negative referents by which the dominant class defines and constitutes their taste and cultural behaviour (Bourdieu, 1984; Swartz, 1997; Veenstra, 2015). The end product of this process is that different cultural forms take on symbolic power of class position and they can be interpreted through the prism of class when in their objectified state and can only be fully appreciated through the embodied character of cultural capital. 
However, according to Savage et al. (2015: 102), one of the primary reasons for the reduced efficacy of focusing upon these highbrow forms as primary drivers of cultural distinction is that since Bourdieu, there have been proliferations of new cultural forms that have not traditionally been viewed as elements of highbrow culture. Instead of labelling all of the cultural forms that either emerged or increased in relevance upon the cultural landscape since this time by the relatively derogatory moniker 'lowbrow', Savage et al. (2015) theorise a new form of culture which they term 'emerging', that they argue is marked less in terms of the actual activities people enjoy, but more in the way that they enjoy them, and talk about them. Other studies have come to similar conclusions about the importance of method of consumption over the substance of what is consumed (Friedman, 2011; Jarness, 2015). Therefore, the force of this argumentation is weighted towards an argument of the increased importance of embodied cultural capital and the decreased importance of objectified cultural capital in structuring culturally based social distinctions.

The difference between highbrow and emerging cultural engagement is thus mostly one born of a generational divide, rather than any significant class or capital difference. This is due to a 'waning self-evidence of highbrow culture' (Van Eijck, 2000, p. 208), along with the proliferation of technologies that facilitate new and more accessible forms of culture. However, some argue that these emerging forms of culture are still not consecrated as legitimate forms of culture, sites where objectified cultural capital could be deployed, but rather have become a site where more embodied forms of capital are deployed (Friedman 2011, 2014; Savage et al., 2015). This then signals a decline of objectified cultural capital in favour of a very embodied cultural capital as forming the basis of social distinction born from culture, particularly among younger generations. Any presence of a type of cultural 'omnivore' as described by American sociologist Richard Peterson (1992; and Simkus, 1992; 
and Kern, 1996) may also exist among younger generations because they are most likely to be upwardly mobile. Indeed, many studies suggest that the upwardly mobile represent the primary example of a site in which we can find the culturally omnivorous (Emmison, 2003; Daenekindt and Roose, 2013; Coulangeon 2015; Friedman, 2012, 2013; Van Eijck and Knulst, 2005;). However, the cultural 'omnivore' as such is not championed as representing patterns of cultural consumption in the United Kingdom (Savage et al., 2015; Warde, Wright, and Gayo-Cal, 2007), and in other context, such as Canada, there is mixed evidence of omnivorism (Gemar, 2018a; 2018b; Veenstra, 2010; 2015).

\section{Bourdieu and the body}

Another crucial consideration for this analysis are the distinctions drawn on the basis of physical lifestyle and appearance. Yoga and meditation involve the active engagement of the body. Likewise, vegetarianism concerns distinctions of which foods to put into one's body. This physical component is the other part of embodied cultural capital for Bourdieu. Bourdieu says that the embodied cultural capital comes 'in the form long-lasting dispositions of the mind and body' (Bourdieu, 1986: 47). Therefore, not only does it consist of the internalised knowledge and appreciation of highbrow forms of culture but it also has to do with distinctions based upon judgments of physical bodies that are capable of displaying cultural capital. For Bourdieu, the presentation of the body and physical activities such as exercise and eating were able to reflect social class in the same way as other forms of culture (Bourdieu, 1984). It was thus all part of the unified habitus. Through pursuant homologies of taste, these physical considerations are likewise grouped into specific spheres of preferences for other cultural activities that denote a similar class position. The concern taken for physical presentation of the body and lifestyle considerations thereof reflected one's social position. By contrast then, physical appearance and physical lifestyle could connote the social position of others. Because the physical presentation of bodies is perhaps the most readily observable 
characteristic by which to create ready distinctions, it is of perhaps more importance than is often afforded it in academic works on class and distinction. On this subject, these words of Bourdieu (1984: 213) still ring true:

Everything seems to indicate that the concern to cultivate the body appears, in its elementary form - that is, as the cult of health - often associated with an ascetic exaltation of sobriety and controlled diet, in the middle classes... These classes, who are especially anxious about appearance and therefore about their body-for-others, go in very intensively for gymnastics, the ascetic sport par excellence, since it amounts to a sort of training (askesis) for training's sake.

While gymnastics may indeed be the ascetic sport par excellence, perhaps today the more apt replacement in this passage would be yoga. Meditation may likewise fall into this category. Vegetarianism (and especially veganism) is certainly a form of ascetic lifestyle being the abstention from certain foods. Given the current cultural landscape then, how are these forms consumed on the cultural map of Britain and on the spectrum of highbrow and emerging culture? In later sections this study performs a multiple correspondence analysis and regression analyses to approach an answer.

Yoga, meditation, and vegetarianism in the cultural West

Both yoga and meditation represent cultural forms that originated from non-native religions and alternative spiritualties to the dominant belief structures of the UK. Vegetarianism is often a dietary prescription associated with the parent religions of these cultural activities. Although Western interactions with Eastern religions dates back to the ancient Greeks, the latter portions of the Nineteenth Century represented a proliferation in physical and intellectual contact with these religions (Federman, 2015; Morton and Morton, 2011; Fuchs, 2005). British sociologist Colin Campbell (2002) speaks of a 'cultic milieu' to describe these alternative spiritualties under the umbrella of a single entity. Campbell (2012: 14) describes 
the constituent parts of this entity when he describes his conceptualisation of this milieu:

It includes all deviant belief systems and their associated practices. Unorthodox science, alien heretical religion, deviant medicine, all comprise elements of such an underground. In addition, it includes the collectivities, institutions, individuals, and media of communication associated with these beliefs. Substantively, it includes the worlds of the occult and the magical, intelligences and lost civilizations, of faith healing and nature cure. This heterogeneous assortment of cultural items can be regarded despite its apparent diversity as constituting a single entity - the entity of the cultic milieu. At the basis of the unifying tendencies is the fact that all these worlds share a common position as heterodox or deviant items in relation to the dominant cultural orthodoxies.

When these alternative spiritualties and cultural forms entered the West through various movements of peoples and ideas, they detached from the political and religious institutions that bound them within their original contexts. This process often came with commercialisation and secularisation (Davies, 2016; Lau, 2000; Shachtman, 2013; York, 2001). As Adorno describes, there were thus instances in which both the producers and consumers sought after profit from these forms 'above and beyond their autonomous essence' (Adorno, [1963] (1989): 99).

\section{Data and methodology:}

To answer the research questions outlined in this paper, this analysis proceeded with a national online survey $(\mathrm{n}=1106)$ conducted in conjunction with the prominent survey company SurveyMonkey, with a completion rate of $79 \%$ (of SurveyMonkey representative population). SurveyMonkey recruits a nationally representative population to which the survey was distributed. Therefore, the population is ultimately self-selected. The results were balanced (by SurveyMonkey) according to census data for age and gender, using quota sampling methods to achieve national representativeness. While other prominent quota 
sampling such as race and geography were not a part of the quota methods of SurveyMonkey, these demographics relatively balanced out themselves (see Table 1), with some variation (e.g. slight under-sampling of non-white ethnicities and moderately over-sampling persons from Scotland). While online quota sample surveys certainly have their drawbacks with respect to the online and non-probabilistic nature of the survey, the national representativeness of this survey can be judged in a comparison of core demographics from this survey with the equivalent population of the UK from the 2011 census (see Table 1).

The sample from this original survey, however, is of similar size and methodology to much previously published literature that has utilised quota sampling to glean a representative sample. While Yang and Banamah (2014) contend that quota samples are not an adequate alternative to probability sampling, some prominent pieces of published scholarship have used them to great effect. For example, Savage et al $(2013 ; 2015)$ utilise a 'nationally representative' quota sample of 1026 in their analysis of social class. While ostensibly also using an online survey of over 160,000 responses, the analytical force in developing the class typologies of this paper comes almost entirely form the quota sample (Mills, 2014; Savage et al, 2013; Savage et al, 2014). This paper does not attempt something as ambitious as creating a new typology of social class, as Savage et al (2013) endeavour. For the purposes of this paper, I argue that the size and composition of the original survey is more than adequate. However, because of the recognised drawbacks of the survey methodology employed in this paper, more unassailable survey data is also used to supplement the original survey where efficacious.

Table 1 also shows the results of the 2015-2016 Taking Part Survey compared to the core demographics of its equivalent census population. The Taking Part Survey (TPS) uses probabilistic methods to achieve its nationally representative sample of England (Department 
for Culture, Media. However, while the original survey is lacking in certain ways at the population level (being self-selecting), the TPS may be said to lack at the sample level (not wholly reflecting its population). This is to say, the demographic breakdown of the TPS sample appears much further from representing the population in some respects. There is a large over sampling of older persons and those from the Northeast of England, and a vast under sampling of those aged 18-29, non-white ethnic groups, and Londoners.

Table 1. National representativeness with key demographic characteristics of the original and Taking Part Survey data for $18+$ populations and samples (OS = original survey) compared to 2011 Census data for the United Kingdom and England

\begin{tabular}{|c|c|c|c|c|}
\hline Survey frequencies* & $\mathrm{OS}(\mathrm{n}=1,106)$ & Census (UK) & Census (England) & TPS $(n=9,963)$ \\
\hline \multicolumn{5}{|l|}{ Age Group* } \\
\hline $18-29$ & $20.8 \%$ & $20.6 \%$ & $20.7 \%$ & $10.4 \%$ \\
\hline $30-44$ & $26.1 \%$ & $26.0 \%$ & $26.3 \%$ & $22.8 \%$ \\
\hline $45-59$ & $29.5 \%$ & $24.8 \%$ & $24.7 \%$ & $24.9 \%$ \\
\hline $60+$ & $23.6 \%$ & $28.5 \%$ & $28.4 \%$ & $41.9 \%$ \\
\hline Female & $519 \%$ & $515 \%$ & $513 \%$ & $549 \%$ \\
\hline Male & $48.1 \%$ & $48.5 \%$ & $48.7 \%$ & $45.1 \%$ \\
\hline \multicolumn{5}{|l|}{ Race } \\
\hline Non-white ethnicities & $9.4 \%$ & $11.1 \%$ & $12.7 \%$ & $8.3 \%$ \\
\hline White ethnicities & $90.6 \%$ & $88.9 \%$ & $87.3 \%$ & $91.7 \%$ \\
\hline \multicolumn{5}{|l|}{ Region } \\
\hline East of England & $10.9 \%$ & $9.2 \%$ & $11.0 \%$ & $11.0 \%$ \\
\hline East Midlands & $4.8 \%$ & $7.2 \%$ & $8.6 \%$ & $9.8 \%$ \\
\hline Jersey & $0.3 \%$ & $0.2 \%$ & - & - \\
\hline London & $12.4 \%$ & $12.8 \%$ & $15.3 \%$ & $9.9 \%$ \\
\hline North East & $2.7 \%$ & $4.2 \%$ & $5.0 \%$ & $10.3 \%$ \\
\hline North West & $9.9 \%$ & $11.2 \%$ & $13.3 \%$ & $13.2 \%$ \\
\hline Northern Ireland & $1.9 \%$ & $2.8 \%$ & - & - \\
\hline Scotland & $11.5 \%$ & $8.6 \%$ & - & - \\
\hline South East & $15.8 \%$ & $13.6 \%$ & $16.3 \%$ & $15.1 \%$ \\
\hline South West & $10.8 \%$ & $8.5 \%$ & $10.2 \%$ & $9.2 \%$ \\
\hline Wales & $4.2 \%$ & $4.9 \%$ & - & - \\
\hline West Midlands & $7.1 \%$ & $8.8 \%$ & $10.5 \%$ & $10.8 \%$ \\
\hline Yorkshire \& the Humber & $7.5 \%$ & $8.3 \%$ & $10.0 \%$ & $10.7 \%$ \\
\hline
\end{tabular}

*Relative frequencies rounded to the nearest tenth and therefore may not add up to $100 \%$

The original survey consisted of many questions that established background and demographic information (Table 4). The remaining questions of the survey asked about cultural choices and behaviours (Tables 2 and 3). Bennet et al. (2009) and Savage et al. (2015) formed a template for which activities would be included in order to achieve a 
representative mix of cultural activities in the United Kingdom. This paper does not attempt to fully define these forms of culture because they were asked in a survey without definition and are therefore open to the interpretation of each individual respondent. However, while there are different types of yoga, meditation and vegetarianism, these are fairly well-defined in the social imagination, particularly yoga and vegetarianism. Indeed, previous surveys that ask about visiting 'vegetarian restaurants' (Savage et al, 2015) and yoga (2015-2016 Taking Part Survey) likewise did not define either term. For the three cultural practices of yoga, meditation, and vegetarianism the questions, relative, and absolute frequencies (Table 2) were:

1. Do you regularly participate in any of the following?

2. Do you follow any of these dietary restrictions?

Table 2. Survey $(\mathrm{n}=1106)$ relative frequencies for meditation, yoga, and vegetarianism

\begin{tabular}{|ccc|}
\hline Meditation & Yoga & Vegetarian (and vegan) \\
\hline $12.8 \%$ & $9.6 \%$ & $15.8 \%$ \\
\hline
\end{tabular}

Table 3. Survey $(n=1106)$ relative frequencies for other cultural variables

\begin{tabular}{llll}
\hline Go to stately homes & $40.2 \%$ & Socialise at home & $63.6 \%$ \\
Go to the opera & $13.2 \%$ & Watch dance or ballet & $17.9 \%$ \\
Listen to jazz & $18.5 \%$ & Listen to hip hop/rap & $14.2 \%$ \\
Listen to rock/indie & $48.5 \%$ & Exercise/go to the gym & $41.2 \%$ \\
Go to gigs & $37.9 \%$ & Go to museums/galleries & $57.9 \%$ \\
Play video games & $34.6 \%$ & Listen to classical music & $38.6 \%$ \\
Watch sports & $47.9 \%$ & Use social media & $67.1 \%$ \\
Go to the theatre & $53.9 \%$ & Drink beer & $51.2 \%$ \\
Do arts and crafts & $35.7 \%$ & Drink wine & $63.5 \%$ \\
\hline
\end{tabular}

This study follows the example of Bourdieu (1984) and more recent studies (Bennett et al., 2009; Friedman, 2014; Hanquinet, Roose, and Savage, 2014; Roose, 2015; Savage et al. 2015) in deploying multiple correspondence analysis (MCA) for the purposes of analysing the patterning of yoga, meditation, and vegetarianism on the cultural map. Multinomial 
logistic regressions of both this original survey and data on yoga from the 2015-2016 Taking Part Survey are then used to supplement the MCA and more narrowly identify independent variables associated with yoga, meditation, and vegetarianism. Multinomial logistic regressions model the probabilities of categorical data given different dependent and independent variables.

Table 4. Survey frequencies of information included in the regression analysis of this paper Original survey $(\mathrm{n}=1106)$

\begin{tabular}{|c|c|}
\hline \multirow{2}{*}{\multicolumn{2}{|c|}{ Age Group }} \\
\hline & \\
\hline $18-29$ & $20.8 \%$ \\
\hline $30-44$ & $26.1 \%$ \\
\hline $45-59$ & $29.5 \%$ \\
\hline $60+$ & $23.6 \%$ \\
\hline \multicolumn{2}{|l|}{ Household Income (after tax) } \\
\hline$£ 0-10,000$ & $11.8 \%$ \\
\hline$£ 10-25,000$ & $23.1 \%$ \\
\hline$£ 25-50,000$ & $37.8 \%$ \\
\hline$£ 50-100,000$ & $20.9 \%$ \\
\hline$£ 100,000+$ & $6.4 \%$ \\
\hline \multicolumn{2}{|l|}{ Personal Education } \\
\hline Postgraduate Degree & $20.5 \%$ \\
\hline No PG Degree & $79.5 \%$ \\
\hline \multicolumn{2}{|l|}{ Gender } \\
\hline Female & $51.9 \%$ \\
\hline Male & $48.1 \%$ \\
\hline \multicolumn{2}{|l|}{ Exercise } \\
\hline Extremely important & $13.8 \%$ \\
\hline Very important & $24.7 \%$ \\
\hline Somewhat important & $40.5 \%$ \\
\hline Not so important & $17.4 \%$ \\
\hline Not at all important & $3.6 \%$ \\
\hline \multicolumn{2}{|l|}{ Religion } \\
\hline Buddhism & $2.2 \%$ \\
\hline Islam & $.7 \%$ \\
\hline Judaism & $.3 \%$ \\
\hline Christianity & $39.3 \%$ \\
\hline Multiple religions & $8.8 \%$ \\
\hline No religion & $47.4 \%$ \\
\hline \multicolumn{2}{|l|}{ Politics } \\
\hline Conservative Party & $20.6 \%$ \\
\hline Green Party & $18 \%$ \\
\hline Labour Party & $26.5 \%$ \\
\hline Liberal Democrats & $13.8 \%$ \\
\hline SNP & $4.5 \%$ \\
\hline UKIP & $10 \%$ \\
\hline Other & $6.6 \%$ \\
\hline
\end{tabular}

MCA is a statistical technique that relationally analyses the various survey response choices, 
or modalities. These relational locations of the collective responses to the survey questions can be displayed spatially these various modalities upon a geometric plane. In general terms, the closer that two modalities are located on the visual map, the more closely they are related. That is to say, if yoga and meditation are close together then those who participate in yoga likely also participate in meditation. Likewise, the further apart yoga and meditation may be, then the less closely that they are related and those who engage in yoga likely do not also consume mediation. This logic holds for all of the active modality points of the MCA.

The MCA analyses the 'active' modalities to generate to generate relative position in the social space. However, 'supplementary' modalities can be inserted into the map and displayed on the same visual maps. Supplementary modalities for this research include variables for age, gender, own education, both parents' education, religion, income, race/ethnicity, and attitudes of exercise. The active categories for this research strictly pertain to cultural behaviours. In the process of analysing the active modalities, MCA creates different axes of separation within the data. The MCA for this research gleaned two primary axes that exhibit cultural cleavages of the United Kingdom. By looking at the axes alongside the coordinates and contributions of the various active categories we can begin to efficacious analyse the MCA for this study. The survey and MCA for this study reveal cultural differences that are fully informed by various class, demographic, and attitude elements.

\section{Results of the multiple correspondence analysis (MCA):}

The first map relating to culture and the place of meditation, yoga, and vegetarianism within this mapping consists of 42 active modalities of culture (Figure 1). The first axis of this MCA separates cultural engagement on the left, and non-engagement in cultural activities on the right. This mirrors the findings in a British context of Bennett et al. (2009), and in other national contexts (Roose, 2015; Veenstra, 2010). Furthest opposed across this axis are those 
who go to the opera and those who do not go to museums or galleries. Across this first axis, yoga, meditation, and vegetarianism are associated with cultural activity. That is, those who regularly engage in these cultural forms are also likely engaged in other cultural activities. Specifically, yoga and meditation are firmly located within a cluster of other cultural activities very much to the left of the first axis. Vegetarianism, however, occupies a more lonesome coordinate closer to Axis 1.

Figure 1. MCA results (showing Axes One and Two) 


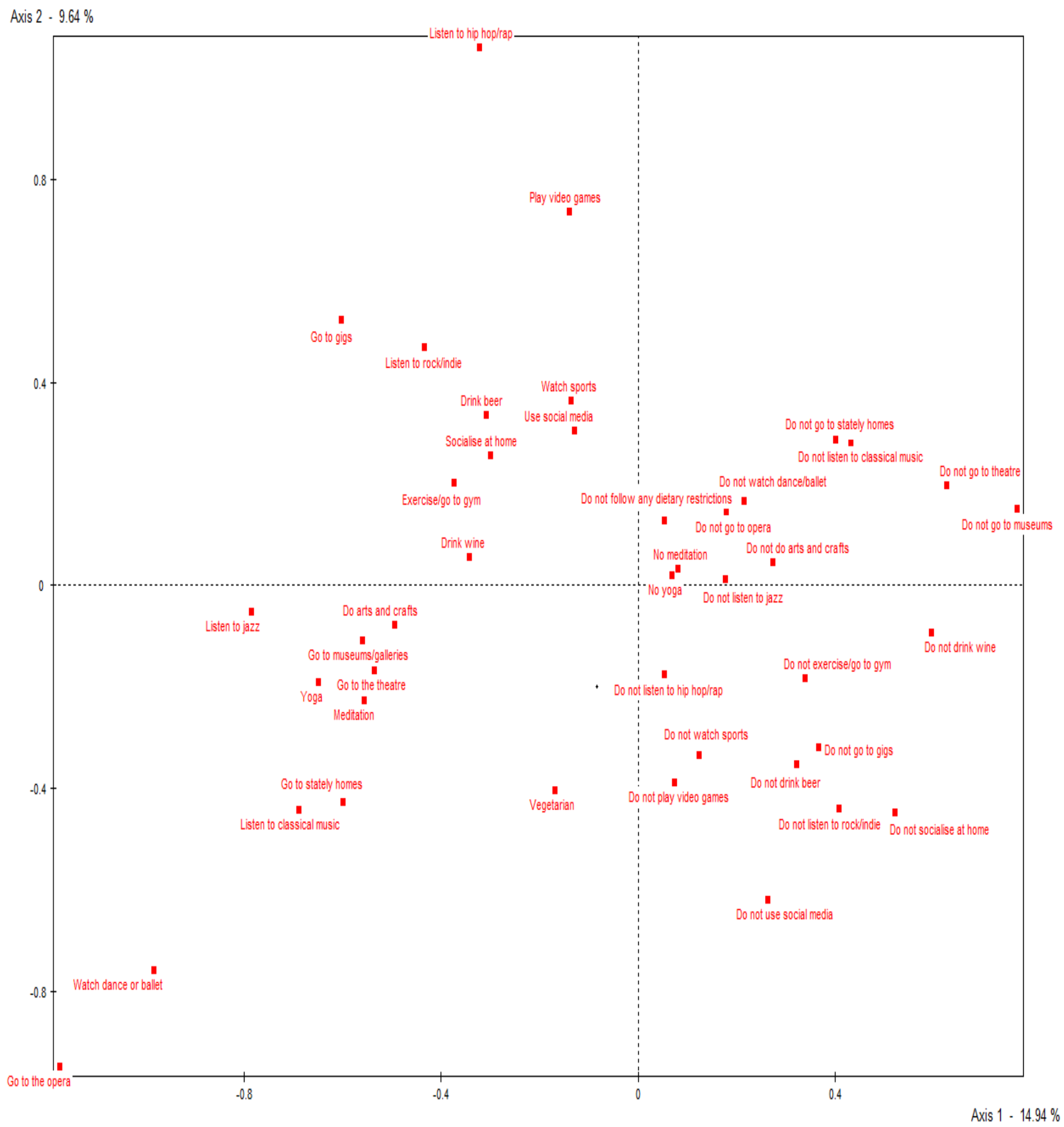

Table 5: MCA eigenvalues and rates of cumulative variance

\begin{tabular}{cccc}
\hline Axis & Eigenvalue & Variance rates & Modified cumulative variance \\
\hline One & .172 & 3.104 & 78.8 \\
Two & .112 & 2.019 & 97.3 \\
\hline
\end{tabular}

To analyse whether there are significant differences in demographics in this space we must 
measure the distances between their coordinates. A distance of .4 will be the minimum threshold between coordinates to say that there is a difference. This, however, is considered a relatively small difference (Bennett et al., 2009; Friedman, 2014). A distance between two demographic coordinated above .5 will be considered a medium difference, above .75 to be a relatively large difference, and above 1.00 to be a very large difference (Friedman, 2014). The supplementary variables are overlaid onto the previous figure for ease of reading. However, the supplementary variables did not affect the spatial ordering of the cultural variables.

The most significant demographic difference across Axis 1 comes from the highest level of personal education. There is a very large distance of 1.21 between those who have a postgraduate degree on the left, and those who have no educational qualifications on the right. Each progressive level of personal educational attainment is reflected progressively from right to left. Other supplementary categories that have significant differences across Axis 1 include household income, race/ethnicity, and importance of exercise. Supplementary categories that did not show significant differences across Axis 1 were age, gender, and religion. Some of the demographic information for Axes one and two are imposed over these axes in Figure 2 to show how these can be graphically displayed.

A coordinate distance of .55 between those whose households bring in $£ 0-10,000$ after taxes and those whose households bring in $£ 100,000+$ represents the difference in household income across Axis 1. However, the largest difference (.67) across Axis 1 with respect to household income comes from those households who earned $£ 0-10,000$ and those who earned between $£ 50$ - 1100,000 . Therefore, it can be said that those who live in households that earned more than $£ 50,000$ after taxes are much more culturally engaged than their less economically advantaged counterparts. 


\section{Figure 2.}

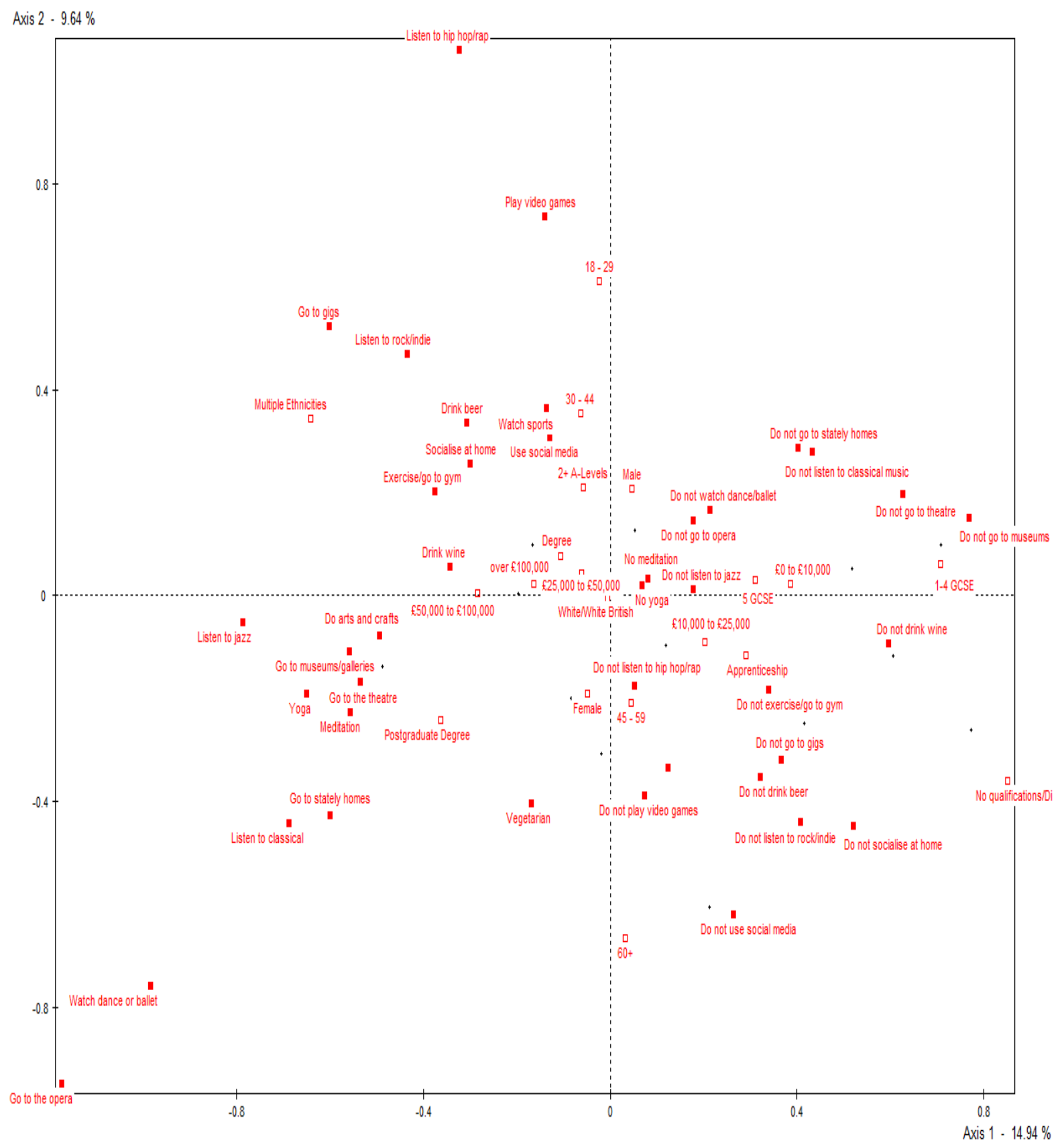

While most racial and ethnic groups by themselves are not of a requisite size to make any profound general statements on cultural engagement and cultural patterning, some trends with respect to race can be seen across Axis 1 . White respondents are located exactly at coordinate 0.00 . Those of non-white ethnicities that were not mixed ethnicities are located a 
significant distance to the right of Axis 1. However, those of mixed ethnicities were located at a distance of .64 to the left of Axis 1 . Therefore, it seems that those of mixed ethnicities may be the most culturally engaged group of any ethnic group and in an age of globalisation and shifting demographics, being of mixed ethnicity may represent its own certain kind of cultural capital.

Axis 2 presents as a type of 'highbrow' and 'lowbrow' axis. It is the type of axis that Bourdieu claimed as of primary importance for its capital construction, and which recent studies have claimed as of primary importance because of its age construction (Bennett et al., 2009; Savage et al., 2015). The cultural activities furthest opposed across Axis 2 are going to the opera on the highbrow (or 'established') side of the axis, and listening to rap and hip-hop on the 'emerging' side of the axis. The next furthest opposed non-repetitive cultural categories across this axis are watching dance and/or ballet to the bottom, and therefore highbrow side, of the axis and playing video games to the top of Axis 2. Those who participate in activities on one side of the axis usually do not partake in the cultural activities on the opposite side of the axis. As readers can view in Figure 3, meditation, yoga, and vegetarianism are all located to the bottom of Axis 2. Yoga and meditation, specifically, are located in a cluster of traditionally highbrow cultural activities that includes going to museums/galleries and the theatre. Vegetarianism is in a location across Axis 2 similar to partaking in the traditionally highbrow cultural forms of listening to classical music and going to stately homes. Yoga, meditation, and vegetarianism fall on the highbrow side of culture, representing new forms of cultural engagement that are being more embraced by the older age groups than other sociologists envisioned with regards to their theorising of the rise of emerging culture. These forms are resistant to this generational divide while presenting the kinds of stratification of capital possession associated with cultural engagement. Therefore, what happens when a relatively new cultural form does not conform to this generational 
difference? Because these forms are not historically consecrated as either high or lowbrow, they are indeed interesting cases that may provide a relatively blank slate. The results of this study suggest that as these generational differences dissipate, there may indeed become more objectified difference again in cultural consumption.

Demographic information that is significant across this second axis includes religion, gender, mother's education, and age. Age is the most important because it both represents the greatest degree of difference and seems to be informative to many of the other demographic differences across Axis 2. Age progressively increases as one moves from top to bottom across Axis 2. The ultimate difference is reflected in the distance between the coordinates of the $18-29$ category and the $60+$ category, which stands at a very large 1.28 . The age difference across this type of an axis confirms previous studies that find these age differences are more pronounced than Bourdieu envisioned during his time and are strongly entrenched within contemporary British society when it comes to affinity for, or aversion of, these types of highbrow cultural forms (Savage et al., 2015, p. 112).

The two demographic differences that are not readily attributed to the very large age difference are a small male/female distance of .40 (with females to the bottom of Axis 2 and males to the top) and mother's education. Those whose mothers have university degrees are located to the highbrow side of Axis 2. The difference across Axis 2 between those whose mothers have university degrees and those whose mothers have no educational qualifications is a medium distance of .55. The fact that personal education and father's education did not represent any kind of significant difference for Axis 2 is indeed an interesting finding. This suggests that mother's education may be the most important aspect in instilling embodied cultural capital for highbrow culture appreciation and participation. The fact that personal educational attainment and father's education do not represent differences across Axis 2 does indeed support, however, the idea that Bourdieu's concepts of the importance of traditionally 
highbrow culture as a function and manifestation of cultural capital are not as relevant contemporarily. Certainly, the absence of any difference in household income across Axis 2 shows that economic capital is no longer a relevant variable in the overall cultural consumption of highbrow v. emerging cultural forms. According to this MCA then, social class first structures participation (participate or not), and then taste (which cultural activities people participate in), confirming previous studies in this regard.

\section{Results of the regression analysis:}

\section{Taking Part Survey (TPS)}

When more conventional bivariate methods of statistical analyses are employed we can get isolated variables without the built-in relational positioning of these cultural forms within the map of wider patterning of culture. Multinomial logistic regression analyses are done to accomplish these bivariate assessments. Only secondary data on yoga can be found outside of the original survey for this paper. The three variables here that are not part of the original survey are personal education (vs. household education), socio-economic classification of occupation, and frequency of engagement with the arts. This section uses data on yoga from the 2015-2016 Taking Part Survey (TPS) to supplement the original survey and analysis because the sample size is much larger and uses probabilistic techniques. Socio-economic variables for economic and cultural capital that are included in the TPS, but not in the original survey, are included in Table 6. This table shows that those with increased levels of both economic and cultural capital are most likely to participate in yoga. 
Table 6. Taking Part Survey (2015-2016) - Response: Yes (have done Yoga in the last 12 months); log odds from the Multinomial Logistic Regressions

\begin{tabular}{|c|c|c|c|c|c|}
\hline \multicolumn{2}{|c|}{$\begin{array}{l}\text { Personal Income } \\
(£ / \text { yr. pre-tax })\end{array}$} & \multicolumn{2}{|l|}{$\begin{array}{l}\text { HRP Socio-Economic } \\
\text { Classification }\end{array}$} & \multicolumn{2}{|c|}{$\begin{array}{c}\text { Number of Arts } \\
\text { engagements (last year) }\end{array}$} \\
\hline$<10,000$ & $-1.390 * * *$ & Higher managerial/professional & $1.131 * * *$ & 0 & $-1.854 * * *$ \\
\hline $10-19,999$ & $-.983 * * *$ & Intermediate occupations & $0.591 * * *$ & 1 & $-1.360 * * *$ \\
\hline $20-34,999$ & $-.718 * *$ & Routine and manual occupations & $\ldots$ & 2 & $-0.792 * * *$ \\
\hline $35-50,000$ & -.390 & & & $3+$ & $\ldots$ \\
\hline$>50,000$ & $\ldots$ & & & & \\
\hline
\end{tabular}

Table 6.

Log odds results from the Multinomial Logistic Regressions of the original survey $(n=1106)$

\begin{tabular}{|c|c|}
\hline \multirow{2}{*}{\multicolumn{2}{|c|}{ Personal Education }} \\
\hline & \\
\hline Postgraduate degree & $0.438 *$ \\
\hline No PG degree & $\ldots$ \\
\hline \multicolumn{2}{|c|}{ Pre-tax Personal Income (£/year) } \\
\hline$<10,000$ & -0.436 \\
\hline $10-19,999$ & 0.309 \\
\hline $20-34,999$ & 0.078 \\
\hline $35-49,999$ & -0.221 \\
\hline$>50,000$ & $\ldots$ \\
\hline \multicolumn{2}{|l|}{ Gender } \\
\hline Female & $1.343 * * *$ \\
\hline Male & $\ldots$ \\
\hline \multicolumn{2}{|l|}{ Age Group } \\
\hline $18-29$ & $0.810 *$ \\
\hline $30-44$ & 0.589 \\
\hline $45-59$ & 0.247 \\
\hline $60+$ & $\ldots$ \\
\hline \multicolumn{2}{|l|}{ Exercise } \\
\hline Not at all important & -1.388 \\
\hline Not so important & $-2.689 * * *$ \\
\hline Somewhat important & $-1.300 * * *$ \\
\hline Very important & $-0.711 *$ \\
\hline Extremely important & $\ldots$ \\
\hline \multicolumn{2}{|l|}{ Religion } \\
\hline Buddhism & $1.324 *$ \\
\hline Islam & -0.053 \\
\hline Judaism & -18.667 \\
\hline Christianity & 1.579 \\
\hline Multiple religions & 1.916 \\
\hline No religion & $\ldots$ \\
\hline Nagelkerke $\mathrm{R}^{2}$ & .181 \\
\hline
\end{tabular}

${ }^{*} \mathrm{p}<.05 ; * * \mathrm{p}<.01 ; * * * \mathrm{p}<.001 ;{ }^{1}$ reference $=$ no yoga, ${ }^{2}$ no meditation, ${ }^{3}$ not vegetarian/vegan 
Original Survey $(n=1106)$

Table 7 presents the multinomial logistic regression models of the original survey data. Reference categories are carefully chosen to avoid a 'reference category problem' that occurs when there is no obvious 'base' category against which to compare the other parameters of an explanatory variable (Gayle and Lambert, 2007). Therefore, the procedure for deciding reference categories in these regression models was to choose one identifiable extreme from each variable that was also a large category by which comparisons with other categories could more efficaciously be made. To this effect, for the explanatory variables with more than two categories, the lowest level of income is chosen as the reference, the highest age group, the 'extremely important' response for the importance of exercise, and finally, the 'no religion' category for religious identification. These selections mitigate the reference category problem by choosing an identifiable base category that is also either the largest category of the explanatory variable or larger than the its opposing category on the other end of the scale (e.g. low vs. high income).

These models did not find linear education stratification at statistically significant levels until one possessed a postgraduate degree, especially for vegetarianism. Household income, unlike personal income with yoga, did not present significant correlation with these practices. Views of religion, political, and especially exercise showed mild to significant differences in who partakes in these practices. While this paper is not of sufficient length to allow such an analysis, the large gender gap in participation in all three of these practices is something that should not be ignored in future study and theorisations of how these forms operate on the cultural landscape and may be related to the 'feminisation' of highbrow culture (Purhonen et al., 2011).

Finally, like other physical activities, yoga shows strong age stratification, with those of 
younger age participating do much higher degrees. However, neither mediation or vegetarianism show such age stratification. The physicality likely dictates yoga's age stratification, even as it appears to be consecrated with traditionally highbrow cultural activities. According to the regression of all of the cultural activities from the original survey, yoga is the only cultural activities on the highbrow side of the second axis that is more likely to be done by younger persons at statistically significant levels. Yoga, meditation, and vegetarianism are the only cultural forms that do not statistically adhere to the assertion of the main driver of taste distinction today as being generational.

Table 7.

Log odds results from the Multinomial Logistic Regressions of the original survey $(n=1106)$

\begin{tabular}{|c|c|c|c|}
\hline & Yoga $^{1}$ & Meditation $^{2}$ & Vegetarian $^{3}$ \\
\hline \multicolumn{4}{|l|}{ Personal Education } \\
\hline Postgraduate degree & 0.438* & 0.167 & $0.761 * * *$ \\
\hline No PG degree & $\ldots$ & $\ldots$ & $\ldots$ \\
\hline \multicolumn{4}{|c|}{ After-tax Household Income ( $£$ /year) } \\
\hline $100,000+$ & -0.436 & -0.938 & 0.063 \\
\hline $50-100,000$ & 0.309 & -0.468 & -0.118 \\
\hline $25-50,000$ & 0.078 & -0.214 & 0.142 \\
\hline $10-25,000$ & -0.221 & -0.179 & -0.137 \\
\hline $0-10,000$ & $\ldots$ & $\ldots$ & $\ldots$ \\
\hline \multicolumn{4}{|l|}{ Gender } \\
\hline Female & $1.343 * * *$ & $0.673 * *$ & $1.083 * * *$ \\
\hline Male & $\ldots$ & $\ldots$ & $\ldots$ \\
\hline \multicolumn{4}{|l|}{ Age Group } \\
\hline $18-29$ & $0.810 *$ & -0.116 & -0.107 \\
\hline $30-44$ & 0.589 & 0.187 & 0.032 \\
\hline $45-59$ & 0.247 & 0.280 & 0.120 \\
\hline $60+$ & $\ldots$ & $\ldots$ & $\ldots$ \\
\hline \multicolumn{4}{|l|}{ Exercise } \\
\hline Not at all important & -1.388 & $-2.388^{*}$ & $-1.385^{*}$ \\
\hline Not so important & $-2.689 * * *$ & $-1.554 * * *$ & $-0.943 * *$ \\
\hline Somewhat important & $-1.300 * * *$ & $-0.879 * *$ & $-0.902 * *$ \\
\hline Very important & $-0.711 *$ & $-0.596 *$ & -0.160 \\
\hline Extremely important & $\ldots$ & $\ldots$ & $\ldots$ \\
\hline \multicolumn{4}{|l|}{ Religion } \\
\hline Buddhism & $1.324 *$ & $2.419 * * *$ & $1.556 * *$ \\
\hline Islam & -0.053 & 0.037 & $-0.704 * *$ \\
\hline Judaism & -18.667 & 0.348 & -0.245 \\
\hline Christianity & 1.579 & 1.042 & -19.077 \\
\hline Multiple religions & 1.916 & $1.319 * * *$ & 0.055 \\
\hline No religion & $\ldots$ & $\ldots$ & $\ldots$ \\
\hline Nagelkerke $\mathrm{R}^{2}$ & .181 & .139 & .152 \\
\hline
\end{tabular}

${ }^{*} \mathrm{p}<.05 ; * * \mathrm{p}<.01 ; * * * \mathrm{p}<.001 ;{ }^{1}$ reference $=$ no yoga, ${ }^{2}$ no meditation, ${ }^{3}$ not vegetarian/vegan 


\section{Discussion and Conclusion:}

Through engaging in this quantitative mapping and regression analysis, answers to our original questions start to emerge. Yoga, meditation, and vegetarianism are likely to be done together. Yoga and meditation are the most likely to be done together. Given their association with Eastern religions and spiritualities, and their current position in a type of both cultic milieu and consumer marketplace, this is perhaps wholly unsurprising. However, it is significant in that while this association may suggest that these forms have not been as secularised (as forms of exercise, mental health, or physical health prescriptions) as some suggest, and are rather mostly appropriated modes of spirituality, importance of exercise is a stronger predictor of participation than is religion. This is true with the exception of Buddhism, which is likewise wholly unsurprising given the socio-historical origins of these forms.

Those who engage in these cultural forms are also likely to be culturally engaged in other areas of their life. They are perhaps more likely to engage in relatively 'highbrow' cultural forms. As compared to other aspects of culture on the highbrow/lowbrow cultural map, which are not characterised by any significant differences in education and income, meditation, yoga, and vegetarianism shows that there may always exist objectified forms of cultural distinction that are engaged by those with more economic and cultural capital and through which distinction is made simply by engaging. These forms maintain large differences in the capital composition of those who are most culturally engaged and those who are not while at the same time resisting the age stratification found in previous studies. This makes these forms more powerful in the accruing and exchange of objectified cultural capital than either traditionally highbrow or emerging cultural forms. 
These three cultural forms then, represent aspects of culture on the highbrow/lowbrow cultural map, that are indeed distinguished by the cultural capital of those who engage them. However, unlike other forms of culture on the cultural map, and contrary to the arguments of previous studies, this holds true regardless of age. While more traditional forms of culture that represented highbrow culture during the time of Bourdieu, these forms no longer hold this same kind of cultural sacredness. Therefore, it can be said that the distinctions made by the kinds of objectified cultural capital bound up in the mere engagement in these activities no longer hold their power of social distinction. This is because the privileged young simply engage their capital in different forms of culture. However, when new cultural forms gain prominence on the cultural landscape and are not already socially categorised as inherently highbrow or lowbrow or haven't been reflexively adjusted to eliminate snobbery, does the social power of their objectified engagement no longer hold sway in contemporary society? The results found in this paper would suggest otherwise. As new cultural forms enter society, these forms must be assigned a certain societal value upon which their worth and the worth of those who take part in them is quickly assessed. Because the sites of cultural engagement addressed in this paper represent ones that are fully stratified without the caveat of age, then perhaps the distinguishing force of more objectified forms of cultural capital may be more prevalent than some recent scholarship allows.

Therefore, the primary argument of this paper is that these three cultural forms represent sites of emerging forms of culture that not only do not fit into previous conceptualisations of emerging culture, but also explicitly exhibit near traditional highbrow cultural forms on the social map. These forms therefore do not need to be theorised through the lens of emerging culture, explaining how they still exhibit similar kinds of distinction as traditional highbrow culture. This is because they already represent rarefied forms of culture that have stratifying effects similar to those of traditional forms of highbrow culture but also do not exhibit the same kind of age stratification that emerging forms exhibit, vis-à-vis traditionally highbrow 
forms. They can therefore also be analysed through the lens of objectified cultural capital, rather than mostly through the lens of embodied cultural capital, which emerging forms have been interpreted through because the distinction associated with them primarily takes place through the 'how' of consumption, rather than the 'what' (Jarness, 2015). Limitations of this study include the method of survey. While online surveys are increasingly more reliable, and Survey Monkey is a reputable survey company, there are always questions of sample composition in any online survey. Areas for further sociological research include qualitatively studying how strong distinction may be within these forms, as displayed by embodied cultural capital possession. There may indeed be strong distinctions between those who, for instance, perform yoga for exercise vs. spirituality, or vegetarians vs. vegans, etc. If Freidman (2014) finds that comedy is a cultural site and prism through which the privileged pathologise those with fewer cultural capital resources, attributing to them diminished 'worth' in an act of creating 'symbolic boundaries' (Lamont, 1992) and 'symbolic violence' (Bourdieu, 1990), how much rifer is the potentiality for those possessing higher forms of capital to create similar distinctions of 'worth' based on the bodies and beliefs of others.

\section{References}

Adorno, T.W. [1963] (1989). The Culture Industry Reconsidered. Routledge.

Bennett, T., Savage, M., Silva, E., Warde, A., Gayo-Cal, M., \& Wright, D. (2009). Culture, Class, Distinction. London; New York: Routledge.

Bourdieu, P. (1984). Distinction: A social critique of the judgement of taste. London: Routledge \& Kegan Paul.

Bourdieu, P. (1990). The Logic of Practice. Stanford, CA: Stanford University Press. Bourdieu, P. (1986). “The forms of capital," in J.G. Richardson (ed.) Handbook of Theory and Research for the Sociology of Education, New York: Greenwood, 241-58. 
Campbell, C., 2002. The cult, cultic milieu, and secularization. In Lööw H. \& J. Kaplan, eds. The Cultic Milieu: oppositional subcultures in an age of globalization. Walnut Creek; Lanham; New York; Oxford: Alta Mira Press, Rowman \& Littlefield Publisher Inc., pp. 12-25.

Coulangeon, P., 2017. Cultural Openness as an Emerging Form of Cultural Capital in Contemporary France. Cultural Sociology, 11(2), pp.145-164.

Daenekindt, Stijn, and Henk Roose. (2013). "Cultural chameleons: Social mobility and cultural practices in the private and public sphere." Acta Sociologica, 56(4), 309-324.

Davies, W., (2016). The happiness industry: how the government and big business sold us well-being, London: Verso.

Emmison, Michael. (2003). "Social Class and Cultural Mobility: Reconfiguring the Cultural Omnivore Thesis.” Journal of Sociology, 39(3), 211-230.

Flemmen, M., Jarness, V. \& Rosenlund, L., 2017. Social space and cultural class divisions: the forms of capital and contemporary lifestyle differentiation. The British Journal of Sociology.

Friedman, S., (2011). The cultural currency of a 'good' sense of humour: British comedy and new forms of distinction. The British Journal of Sociology, 62(2), pp.347-370.

Friedman, S., 2012. Cultural omnivores or culturally homeless? Exploring the shifting cultural identities of the upwardly mobile. Poetics, 40(5), pp.467-489.

Friedman, S., (2013). The Price of the Ticket: Rethinking the Experience of Social Mobility. Sociology, 48(2), pp.352-368.

Friedman, S. (2014). Comedy and Distinction: The cultural currency of a 'good' sense of humour. London: Routledge, Taylor \& Francis Group.

Fuchs, C. (2005). Yoga. In K. Von Stuckrad (Ed.), The Brill Dictionary of Religion. (2nd 
ed.). [Online]. Leiden: Brill. Available from:

http://ezphost.dur.ac.uk/login?url=https://search.credoreference.com/content/entry/bril $\underline{\operatorname{ldr} / \text { yoga/0?institutionId=1856. }}$.

Gemar, A. (2018a). Which sports do you like? Testing intra-domain omnivorousness in Canadian following of professional sport. International Review for the Sociology of Sport. DOI: 10.177/1012690217749243.

Gemar, A. (2018b). Sport in broader leisure lifestyles: An analysis of the professional sport consumer's cultural engagement. International Review for the Sociology of Sport. DOI: $10.1177 / 1012690218807363$.

Hanquinet, L., Roose, H., \& Savage, M. (2014). 'The Eyes of the Beholder: Aesthetic Preferences and the Remaking of Cultural Capital'. Sociology, 48(1), 111-132.

Hasselle-Newcombe, S., 2005. Spirituality and 'Mystical Religion' in Contemporary Society: A Case Study of British Practitioners of the Iyengar Method of Yoga.Journal of Contemporary Religion, 20(3), pp.305-322.

IBISWorld. (2016). "Pilates and Yoga Studios in the UK: Market Research Report." IBSISWorld. March 2016). http://www.ibisworld.co.uk/market-research/pilates-yogastudios.html

Jarness, V., 2015. Modes of consumption: From 'what' to 'how' in cultural stratification research. Poetics, 53, 65-79.

Kobayashi, K., Jackson, S.J. \& Sam, M.P., 2017. Multiple dimensions of mediation within transnational advertising production: cultural intermediaries as shapers of emerging cultural capital. Consumption Markets \& Culture, pp.1-18.

Lamont, M. (1992). Money, Morals, and Manners: The culture of the French and American upper-middle class. Chicago: University of Chicago Press.

Lau, K.J., (2000). New age capitalism: making money east of Eden, Philadelphia: University 
of Pennsylvania Press.

Lizardo, O. \& Skiles, S., 2012. Reconceptualizing and Theorizing "Omnivorousness":

Genetic and Relational Mechanisms. Sociological Theory, 30(4), 263-282.

Lizardo, O. \& Skiles, S., 2015. Musical taste and patterns of symbolic exclusion in the United States 1993-2012: Generational dynamics of differentiation and continuity. Poetics, $53,9-21$.

Morton, S.L. and Morton. (2011). Meditation. In W. Roof \& M.

Juergensmeyer, Encyclopedia of global religions. [Online]. Thousand Oaks: Sage Publications. Available from:

http://ezphost.dur.ac.uk/login?url=https://search.credoreference.com/content/entry/sag egr/meditation/0?institutionId=1856.

Park, C.L., Braun, T. \& Siegel, T., 2015. Who practices yoga? A systematic review of demographic, health-related, and psychosocial factors associated with yoga practice. Journal of Behavioral Medicine, 38(3), pp.460-471.

Peterson, R. A. (1992). “Understanding audience segmentation: from elite and mass to omnivore and univore." Poetics, 21(4), 243-258.

Peterson, R. A., \& Kern, R.M. (1996). “Changing Highbrow Taste: From Snob to Omnivore." American Sociological Review, 61(5), 900-907.

Purhonen, S., Gronow, J. \& Rahkonen, K., 2011. Highbrow culture in Finland: Knowledge, taste and participation. Acta Sociologica, 54(4), pp.385-402.

Mintel. (2014). "Number of Global Vegetarian Food and Drink Product Launches Doubles Between 2009 and 2013.” Mintel. October 1 1t, 2014 http://www.mintel.com/presscentre/food-and-drink/number-of-global-vegetarian-food-and-drink-product-launchesdoubles-between-2009-and-2013

Roose, H., (2015). Signs of ‘emerging' Cultural Capital? Analysing Symbolic Struggles 
Using Class Specific Analysis. Sociology, 49(3), 556-573.

Savage, M., Devine, F., Cunningham, N., Taylor, M., Li, Y., Hjellbrekke, J., et al. (2013). A new model of social class: Findings from the BBC's Great British Class Survey experiment. Sociology, 47(2), 219-250.

Savage, M. (2015). Social Class in the 21st century. London: Pelican, an imprint of Penguin Books.

Shachtman, N., (2013). “In Silicon Valley, Meditation Is No Fad. It Could Make Your Career.” Wired, Conde Nast, 18 June 2013, www.wired.com/2013/06/meditation$\underline{\text { mindfulness-silicon-valley/. }}$

Van Eijck, K., \& Knulst, W. (2005). "No More Need for Snobbism: Highbrow Cultural Participation in a Taste Democracy." European Sociological Review, 21(5), 513-528.

Warde, A., Wright, D., \& Gayo-Cal, M. (2007). “Understanding Cultural Omnivorousness: Or, the myth of the cultural omnivore." Cultural Sociology, 1(2), 143-164.

Wieczner, Jen. (2016). "Meditation Has Become a Billion Dollar Business.” Fortune. March 12, 2016. http://fortune.com/2016/03/12/meditation-mindfulness-apps/

York, M., 2001. New Age Commodification and Appropriation of Spirituality. Journal of Contemporary Religion, 16(3), pp.361-372. 